\title{
A MET Isn't Just a Baseball Player from New York
}

\author{
DENNIS G. 0'CONNELL* AND JANELLE K. O'CONNELL† \\ *University of Texas Health Science Center at San Antonio, San Antonio, Texas; \\ ${ }^{\dagger}$ University of Texas at San Antonio, San Antonio, Texas
}

\begin{abstract}
Most of us hold opinions on contemporary issues in work practice, in all its broad dimensions. "Sounding Board" is a regular feature of this publication, designed to provide a forum for expressing such views, whether mainstream or controversial.

The opinions expressed in this section may not necessarily represent the views of the editor, the publisher, or the editorial board but are intended to stimulate discussion or to provoke a response. Readers who wish to comment on the ideas put forth in "Sounding Board" should address their comments to the editor.
\end{abstract}

Keywords: Energy expenditure; Oxygen consumption; Work

Baseball season is in full-swing and for many fans this means rooting for the N.Y. Mets. However, the term METs has another, more important meaning for those interested in WORK. This meaning is especially important to clinicians who might treat the baseball player, management, front office staff (secretaries and administrative personnel), maintenance workers, or members of the stadium grounds crew. This article defines metabolic equivalents (METs) and discusses several important and often neglected considerations for the use of METs in a rehabilitative setting.

Readers of $W O R K$, and others who study or rehabilitate workers, must accurately describe the intensity of job tasks. Clinicians must be knowledgable about METs because they must make informed decisions regarding workers' return to work. Work is defined as the product of force multiplied by distance. Work can also be defined as the energy required to perform a mechanical task (Preventive and Rehabilitative Exercize Committee of the ACSM, 1991).
Regardless of how work is defined, professional baseball players, as well as baseball fans, are metabolically inefficient workers. As we work, energy and heat are generated during cellular catabolic reactions. In fact, during each minute of work even the most skilled ball player creates several times more heat energy than chemical energy. While playing baseball, a New York Met has an optimal efficiency of $\sim 20 \%-25 \%$, converting a small amount of chemical energy to mechanical energy. The remaining $70 \%-75 \%$ of the energy is given off as heat energy.

It is technically difficult to measure fine gradations in heat energy (kilocalories or kilojoules) given off by the human body. Thus, measuring the chemical energy of an individual is often substituted for the measurement of heat energy. Chemical energy can be measured using a technique known as indirect calorimetry. The technique involves measuring the volume of air an individual consumes within a given time frame and simultaneously examining differences in in- 
spired and expired oxygen and carbon dioxide concentrations. The amount of oxygen used for metabolism is termed oxygen consumption $\left(\mathrm{Vo}_{2}\right)$.

Oxygen consumption can be described in absolute (liters/minute) or weight relative $\left(\mathrm{ml} / \mathrm{kg}^{-1} /\right.$ $\mathrm{min}^{-1}$ ) terms. If described in absolute terms, an individual's oxygen consumption (liters/minute) can be converted to a heat-energy equivalent, kilocalories (kcals), multiplying by the constant 5.0. Clinicians usually wish to relate energy expenditure to an individual worker. To do this, the $\dot{\mathrm{VO}}_{2}$ of the work task is divided by the body weight $(\mathrm{kg})$ of the worker. Thus, if a $100-\mathrm{kg}$ baseball player was jogging in the outfield at an oxygen consumption of $2 \mathrm{l} / \mathrm{min}$, his $\mathrm{VO}_{2}$ would be $20 \mathrm{ml} /$ $\mathrm{kg}^{-1} / \mathrm{min}^{-1}$.

METs are easy-to-use numerical values that represent an individual's energy expenditure. METs are units of common currency among exercise physiologists, therapists, ergonomists, and some medical specialists (especially cardiologists). One MET is equal to $3.5 \mathrm{ml} / \mathrm{kg}^{-1} / \mathrm{min}^{-1}$. This means that during each minute of rest an individual consumes $3.5 \mathrm{ml}$ of oxygen per $\mathrm{kg}$ of body weight. To determine the MET level of the jogging baseball player, divide $20 \mathrm{ml} / \mathrm{kg}^{-1} / \mathrm{min}^{-1}$ by $3.5 \mathrm{ml} / \mathrm{kg}^{-1} / \mathrm{min}^{-1}$. This ball player would be jogging at a 5.7 MET intensity. MET values increase proportionally with the consumption of oxygen and with the intensity of work performed.

Diagnostic exercise tests or functional work capacity tests reveal the maximum MET level a patient or worker can achieve. The clinician uses maximum MET information to assist the worker in progressing to a MET level equivalent to a desired job or occupation.

Metabolic tables (print or software) provide a quick reference for a variety of tasks and are an important clinical tool. Since METs primarily represent the intensity of work, they should be used carefully, keeping in mind the following limitations:

1. MET tables are often developed based on data from a single subject or from small numbers of subjects. For example, Durnin and Passmore, (1967) generated a great deal of data on individuals or small groups of subjects. Although
Durnin and Passmore are referenced as a source in a large table in a recently published text (McArdle, Katch, and Katch, 1991), no mention is made of how or on whom the original data was collected. While secondary sources are excellent reference tools, the clinician should locate and review original sources so they can make educated decisions. Authors who extrapolate from single data points make an assumption that during work there is a consistent mathematical relationship between body weight and energy expenditures. This is a proper assumption for some but not all work tasks. Factors such as gender, age, environmental conditions, efficiency of the worker and machinery, and fitness level of the worker impact on test results. These factors should be considered as potential confounders to the application of tabular data.

2. The health status of the subjects on whom the tabular data was generated may be different from your patient/client (Bannister and Brown, 1968). Durnin and Passmore (1955) listed values ranging from $2.5-4.0 \mathrm{kcal} / \mathrm{min}$ for carrying out personal necessities, that is, washing hands and face, shaving, brushing hair, and dressing. Do these values accurately reflect energy expenditures for the older individual with chronic bronchitis preparing for work? Examination of published energy expenditure data reveals the use of convenience samples from apparently healthy workers or from human lab rats (students or faculty) who are usually quite fit. Clinicians often evaluate workers who are recovering from injuries and who hope to return to work. Energy expenditure data generated on healthy workers must be used cautiously by those who are injured.

3. Published energy expenditure data ages; work tasks and occupations change. For example, the energy expenditure of driving a tractor in 1966 was much greater than that required for driving today's air-conditioned, power-steering tractors. Older data may actually overestimate the actual metabolic cost of some activities.

4. Workers don't do tasks in the same way, and 
not all tabular data can be generalized (Kiser and Rodgers, 1986).

5. Job titles may be confusing and may differ from one industry to the next. Job tasks may differ from the same job title (Kiser and Rodgers, 1986).

6. Within a single job or task there can be different levels of effort due to varying product sizes, cycle times, or postural requirements (Kiser and Rodgers, 1986).

7. A worker's pace determines the metabolic demand of the task. If the worker is allowed to vary the pace, then she can perform the task in varying states of health (Kiser and Rodgers, 1986).

8. Strength, reach, postural, and other physical, perceptual, or psychological demands (not metabolic demands) may limit job performance (Kiser and Rodgers, 1986).

In summary, the purpose of this review was to draw attention to potential problems involved with interpreting and utilizing energy expenditure data. Clinicians must critically review energy ex- penditure data used for injury-prevention, reh bilitative, or return-to-work programs.

When you think of METs, remember that the are the universally accepted term describing th work the New York Mets or other workers pe form.

\section{REFERENCES}

Preventive and Rehabilitative Exercise Committee the American College of Sports Medicine (1991) Guidelines for Exercise Testing and Prescription. Philade phia, PA: Lea \& Febiger.

Bannister, E. W., and Brown, S. R. (1968). The relati energy requirements of physical activity. In Exercise physic ogy H. B. Falks (Ed.), New York: Academic Pres pp. 267-322.

Durnin, J. V. G. A., and Passmore, R. (1955). Huma energy expenditure. Physiol Rev, 35, 801-840.

Durnin, J. V. G. A., and Passmore, R. (1967). Energ work and leisure. London: Heinemann Education Books.

Kiser, D. M., and Rodgers, S. H. (1986). Appendix 4 Human capacities and job demands in ergonomic design $f$ people at work by the Ergonomics Group, Eastman Kode Company. New York: Van Nostrand Rheinhold.

McArdle, W. D., Katch, F. L., and Katch, V. I (1991). Exercise physiology: Energy, nutrition, and hume performance. Philadelphia, PA: Lea \& Febiger. 